УДК $536.24: 697.134$

\title{
ЧИСЕЛЬНЕ МОДЕЛЮВАННЯ ТРИПОВЕРХОВОЇ БУДІВЛІ 3 ПРИВІКОННИМИ ЗАГЛИБЛЕННЯМИ
}

Новіцька М.П., канд. техн. наук

Інститут технічної теплофізики НАН України, вул. Желябова, 2, а, Київ, 03680, Україна

Проведено дослідження впливу привіконних заглиблень на теплообмін триповерхової будівлі, що знаходиться у потоці повітря. Зіставлені коефіцієнти теплообміну будівлі 3 гладкою поверхнею із будівлею, що має привіконні заглиблення, глибиною 10 см. Визначено, що при чисельних розрахунках теплообміну та аеродинаміки будівель необхідно враховувати наявність на фасаді привіконних заглиблень.

Библ. 9, рис. 3.

Проведено численное исследование влияния приоконных ниш на теплообмен трехэтажного здания находящегося в потоке воздуха. Сопоставлены коэффициенты теплообмена здания с гладкими стенками и здания имеющего приоконные ниши глубиной 10 см. Показано, что при численном расчете теплообмена и аэродинамики зданий необходимо учитывать наличие на фасаде приоконных ниш.
Numerical simulation of windows inset influence on heat transfer of threestoried buildings, located in the wind flow, has been carried out. Surface heat exchange coefficient for buildings with $10 \mathrm{~cm}$ inset value for windows and plain walls has been compared. It is shown that during the numerical simulation of heat transfer and aerodynamics of buildings the existence of windows inset on the facade should be taken into account..

Ключові слова: теплообмін, аеродинаміка, будівля, числове моделювання.

$a, \mathrm{M}^{2} / \mathrm{c}$ - коефіцієнт температуропровідності;

$C$ - емпіричний коефіцієнт;

$H$, м - висота будівлі;

$k, \mathrm{M}^{2} / \mathrm{c}^{2}$ - турбулентна кінетична енергія;

$\mathrm{n}$ - експериментально визначений показник ступеня;

$p$, Па - тиск;

$t, \mathrm{~K}$ - температура;

$U, \mathrm{~m} / \mathrm{c}$ - модуль вектора швидкості вітру;

$u, v, w, \mathrm{~m} / \mathrm{c}$ - проекції вектора швидкості на осі $x$,

$y, z$ прямокутної системи координат;

$x, y, z$, м - поперечна, поздовжня і вертикальна прямокутні координати;

$\alpha$ - коефіцієнт тепловіддачі, Вт/( $\left.\mathrm{M}^{2} \cdot \mathrm{K}\right)$;

Нині все більший інтерес представляє комп'ютерне моделювання будівель, як окремих [1-3] так і цілих масивів міста із щільною забудовою $[4,5]$. Чисельне моделювання в цьому випадку $€$ інструментом для визначення різних характеристик, таких як вітрові навантаження, коефіцієнти тепло- і масовіддачі на поверхні будівель, комфортність вітрових умов в пішохідній зоні, на балконах [6] і т. ін. Крім чисельного моделювання, паралельно також розвиваються $\sigma$ - емпіричний коефіцієнт;

$\varepsilon, \mathrm{M}^{2} / \mathrm{c}^{3}$ - швидкість дисипації кінетичної енергії турбулентності;

$v, \mathrm{M}^{2} / \mathrm{c}$ - коефіцієнт кінематичної в'язкості;

$\rho, \kappa г / \mathrm{M}^{3}-$ густина.

\section{Індекси:}

0 - параметри, розташування яких, є стандартним для анемометра метеостанції;

$k$ - кінетична енергія;

$\varepsilon$ - швидкість дисипації кінетичної енергії турбулентності;

$\mu-$ кінематична в'язкість;

eff- ефективний.

експериментальні методи дослідження. Так, наприклад, роботи $[7,8]$ присвячені експериментальному дослідженню будівель прямокутної форми без додаткових архітектурних елементів.

Всі розглянуті будівлі, як правило, $\epsilon$ погано обтічними тілами 3 відривною зоною пограничного шару. В даний час відомо і широко використовується на практиці велика кількість методів і способів управління пограничним шаром. Одним $з$ них є розташування заглиблень 
на поверхні погано обтічного тіла. При цьому наявність таких заглиблень може, як знизити, так і збільшити тепловіддачу з поверхні. Метою даної роботи було моделювання двох триповерхових адміністративних будівель 3 привіконними заглибленнями і порівняння їх аеродинамічних i теплообмінних характеристик з моделлю будівлі такої ж форми, але з гладкими огороджувальними конструкціями.

В роботі [3] представлені результати чисель- ного дослідження тепловіддачі 3 наружних поверхонь двох триповерхових адміністративних будівель без привіконних заглиблень. Наведено залежності коефіцієнтів тепловіддачі с поверхонь будівлі від швидкості вітрового потоку.

У цій роботі розглянемо випадок поздовжнього обтікання вітровим потоком таких же двох триповерхових адміністративних будівель довжиною 60 м, шириною 18 м і висотою 10,6 м, об'єднаних спільним переходом (рис. 1).

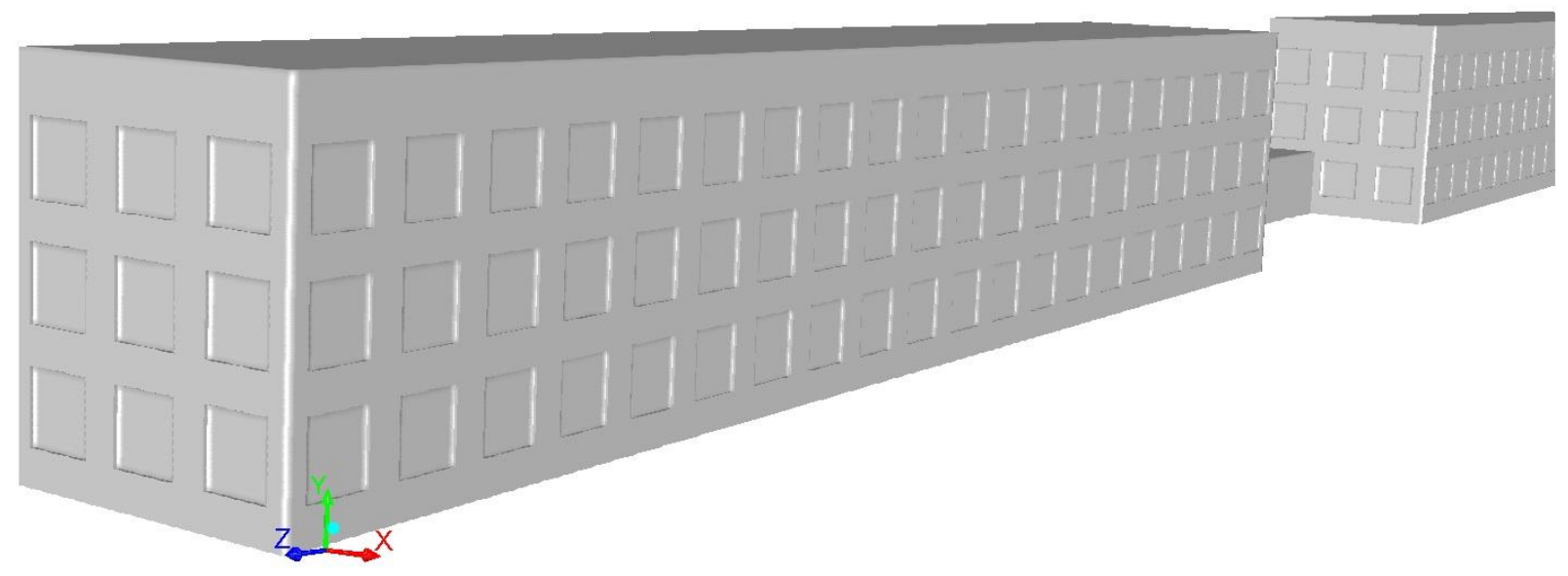

Рис. 1. Зовнішній вигляд будівлі, ще розраховується.

На поверхні яких, розташовані привіконні заглиблення глибиною 10 см. Завдання вирішувалося чисельно, рішенням системи рівнянь збереження маси, кількості руху, енергії і турбулентного переносу. Для замикання системи рівнянь турбулентного переносу використовувалась $k$ - $\varepsilon$ модель турбулентності.

Розмір розрахункової області залежав від висоти будівлі $H$. Цей розмір може суттєво впливати на отримане рішення. При недостатній висоті області рішення граничні умови зверху та по боках будівлі можуть впливати на поле швидкості, яке в свою чергу впливає на інші параметри, такі як поле температури, поле кінетичної енергії і т. ін. У цьому випадку розміри розрахункової області перед будівлею, за нею і до верхньої межі становили відповідно $4 H \times 10 H \times 4 H$. Використовували сітку 35 млн. розрахункових вузлів, що дозволило отримати прийнятну точність розрахунку.

На вході в розрахункову область задавався вертикальний профіль швидкості, який описував- ся степеневим законом виду

$U(z)=U_{o}\left(\frac{z}{z_{0}}\right)^{n}$,

де $U(z)$ - швидкість вітру, м/с на висоті $z, \mathrm{~m} ; U_{0}$ - швидкість вітру, м/с, виміряна на висоті $z_{0}$, м. У цьому випадку на висоті $z_{0}=5 \mathrm{M}, U_{0}=5 \mathrm{~m} / \mathrm{c}$. $n$ - експериментально визначений показник ступеня, який залежить від типу місцевості. Так як досліджувані будівлі знаходяться в зоні міської забудови, то даний показник дорівнює 0,4.

Температура повітря $t$, що омиває будівлю, дорівнювала $-12{ }^{\circ} \mathrm{C}$. Температура поверхні огороджувальних конструкцій $-7^{\circ} \mathrm{C}$.

Система рівнянь турбулентного переносу імпульсу і енергії розглядалась у вигляді

$\frac{\partial u}{\partial x}+\frac{\partial v}{\partial y}+\frac{\partial w}{\partial z}=0$

$\frac{\partial u^{2}}{\partial x}+\frac{\partial u v}{\partial y}+\frac{\partial u w}{\partial z}=-\frac{1}{\rho} \frac{\partial p}{\partial x}+2 \frac{\partial}{\partial x}\left[v_{e f f} \frac{\partial u}{\partial x}\right]+$

$+\frac{\partial}{\partial y}\left[v_{e f f}\left(\frac{\partial u}{\partial y}+\frac{\partial v}{\partial x}\right)\right]+\frac{\partial}{\partial z}\left[v_{e f f}\left(\frac{\partial u}{\partial z}+\frac{\partial w}{\partial x}\right)\right] ;$ 


$$
\begin{aligned}
& \frac{\partial v u}{\partial x}+\frac{\partial v^{2}}{\partial y}+\frac{\partial v w}{\partial z}=-\frac{1}{\rho} \frac{\partial p}{\partial y}+\frac{\partial}{\partial x}\left[v_{\text {eff }}\left(\frac{\partial v}{\partial x}+\frac{\partial u}{\partial y}\right)\right]+ \\
& +2 \frac{\partial}{\partial y}\left[v_{\text {eff }} \frac{\partial v}{\partial y}\right]+\frac{\partial}{\partial z}\left[v_{\text {eff }}\left(\frac{\partial v}{\partial z}+\frac{\partial w}{\partial y}\right)\right] ; \\
& \frac{\partial w u}{\partial x}+\frac{\partial w v}{\partial y}+\frac{\partial w^{2}}{\partial z}=-\frac{1}{\rho} \frac{\partial p}{\partial z}+\frac{\partial}{\partial x}\left[v_{\text {eff }}\left(\frac{\partial w}{\partial x}+\frac{\partial u}{\partial z}\right)\right]+ \\
& +\frac{\partial}{\partial y}\left[v_{\text {eff }}\left(\frac{\partial w}{\partial y}+\frac{\partial v}{\partial z}\right)\right]+2 \frac{\partial}{\partial z}\left[v_{\text {eff }} \frac{\partial w}{\partial z}\right] ; \\
& \frac{\partial u T}{\partial x}+\frac{\partial v T}{\partial y}+\frac{\partial w T}{\partial z}= \\
& =\frac{\partial}{\partial x}\left(a_{\text {eff }} \frac{\partial T}{\partial x}\right)+\frac{\partial}{\partial y}\left(a_{\text {eff }} \frac{\partial T}{\partial y}\right)+\frac{\partial}{\partial z}\left(a_{\text {eff }} \frac{\partial T}{\partial z}\right),
\end{aligned}
$$

де $v_{\text {eff }}=v+v_{\mathrm{t}}, a_{\text {eff }}=a+\frac{v_{\mathrm{t}}}{\sigma_{T}}$.

Для замикання системи рівнянь турбулентного переносу використовувалась $k$ - $\varepsilon$ модель турбулентності, що описується системою рівнянь:

$$
\begin{aligned}
& \frac{\partial u k}{\partial x}+\frac{\partial v k}{\partial y}+\frac{\partial w k}{\partial z}=\frac{\partial}{\partial x}\left[\left(v+\frac{v_{t}}{\sigma_{k}}\right) \frac{\partial k}{\partial x}\right]+ \\
& +\frac{\partial}{\partial y}\left[\left(v+\frac{v_{t}}{\sigma_{k}}\right) \frac{\partial k}{\partial y}\right]+\frac{\partial}{\partial z}\left[\left(v+\frac{v_{t}}{\sigma_{k}}\right) \frac{\partial k}{\partial z}\right]+v_{t} S^{2}-\varepsilon ; \\
& \frac{\partial u \varepsilon}{\partial x}+\frac{\partial v \varepsilon}{\partial y}+\frac{\partial w \varepsilon}{\partial z}=\frac{\partial}{\partial x}\left[\left(v+\frac{v_{t}}{\sigma_{\varepsilon}}\right) \frac{\partial \varepsilon}{\partial x}\right]+\frac{\partial}{\partial y}\left[\left(v+\frac{v_{t}}{\sigma_{\varepsilon}}\right) \frac{\partial \varepsilon}{\partial y}\right]+ \\
& \left.+\frac{\partial}{\partial z} \mid\left(v+\frac{v_{t}}{\sigma_{\varepsilon}}\right) \frac{\partial \varepsilon}{\partial z}\right]+C_{1} \frac{\varepsilon}{k} v_{t} S^{2}-C_{2} \frac{\varepsilon^{2}}{k}
\end{aligned}
$$$$
\text { де }=\left[\left(\frac{\partial u}{\partial y}+\frac{\partial v}{\partial x}\right)^{2}+\left(\frac{\partial v}{\partial z}+\frac{\partial w}{\partial y}\right)^{2}+\left(\frac{\partial w}{\partial x}+\frac{\partial u}{\partial z}\right)^{2}+\right.
$$$$
\left.+2\left(\frac{\partial u}{\partial x}\right)^{2}+2\left(\frac{\partial v}{\partial y}\right)^{2}+2\left(\frac{\partial w}{\partial z}\right)^{2}\right]^{0,5}
$$$$
v_{t}=C_{\mu} \frac{k^{2}}{\varepsilon} ; C_{\mu}=0,09 ; C_{1}=1,44 ; C_{2}=1,92 ; \sigma_{k}=1 ;
$$

$\sigma=1,3$.

Пристінкові функції визначалися згідно роботи [9].

Система диференціальних рівнянь із зазначеними граничними умовами була вирішена чисельно 3 використанням методу контрольного об'єму. Із рішення системи рівнянь визначалися поля швидкості і температури. На підставі отриманих результатів розраховувалися значення коефіцієнтів тепловіддачі на поверхнях будівлі.

Порівняння одержаних розподілів коефіцієнтів тепловіддачі на боковій поверхні будівлі, із значеннями коефіцієнтів тепловіддачі будівлі без привіконних заглиблень [3] представлені на рис. 2.

Як видно 3 рисунка, при інших рівних умовах, істотний вплив на коефіцієнт тепловіддачі надає форма поверхні конструкції. Зберігається тенденція збільшення коефіцієнтів тепловіддачі до кромки будівлі, 3 боку набігаючого потоку. Однак як показано на рисунку 2 коефіцієнт тепловіддачі на кромці будівлі стає меншим, ніж при гладких стінках. При цьому збільшуються величини локальних коефіцієнтів тепловіддачі в центрі будівлі, на ділянках поверхні поза межами привіконних заглиблень. Локальні коефіцієнти тепловіддачі усередині привіконних ніш знижуються за рахунок складної аеродинаміки біля такої поверхні (рис. 3). Така ситуація може суттєво зменшити втрати тепла, так як основні втрати через огороджувальні конструкції приходяться саме на вікна. Як показано, на рисунку 3, наявність привіконних заглиблень суттєво впливає на аеродинаміку навколо будівлі. Швидкість вітру на рисунку відображається хвилеподібною кривою. Тобто наявність привіконних заглиблень, призводить до додаткового вихроутворення i відповідно перерозподілу енергії потоку. Вплив привіконних заглиблень на аеродинаміку потоку поширюється на відстань до 1 метра від поверхні конструкції.

\section{Висновки}

- Наявність привіконної заглиблень суттєво впливає на тепловіддачу з поверхні будівлі

- Надалі необхідно дослідити вплив глибини привіконних заглиблень на тепловіддачу і аеродинаміку навколо будівлі і визначити іï оптимальне значення для зниження тепловіддачі 3 поверхні будівлі. 


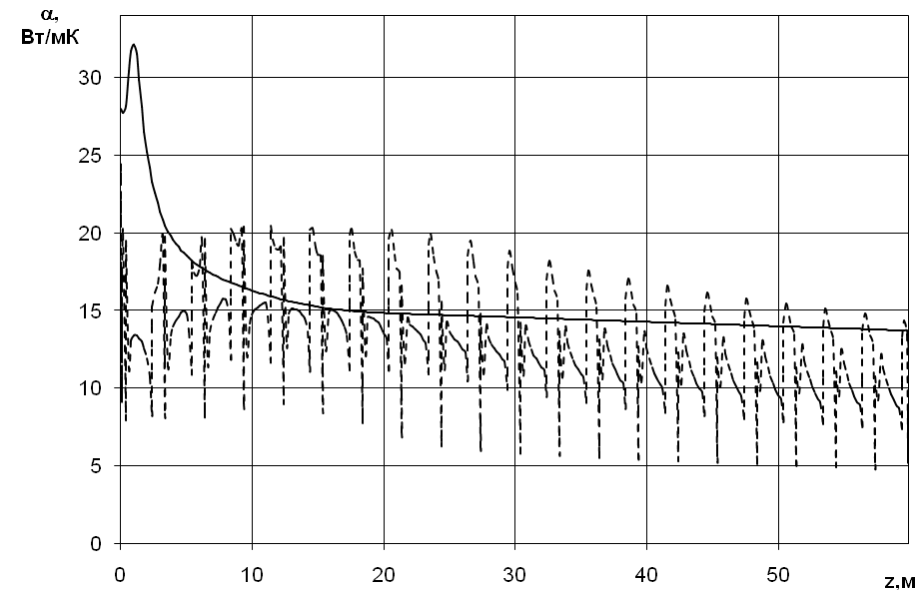

Рис. 2. Розподіл коефіціснтів тепловіддачі уздовж поверхні бокової стіни на висоті 5 м від поверхні землі. - без привіконних заглиблень; - - - із привіконними заглибленнями.

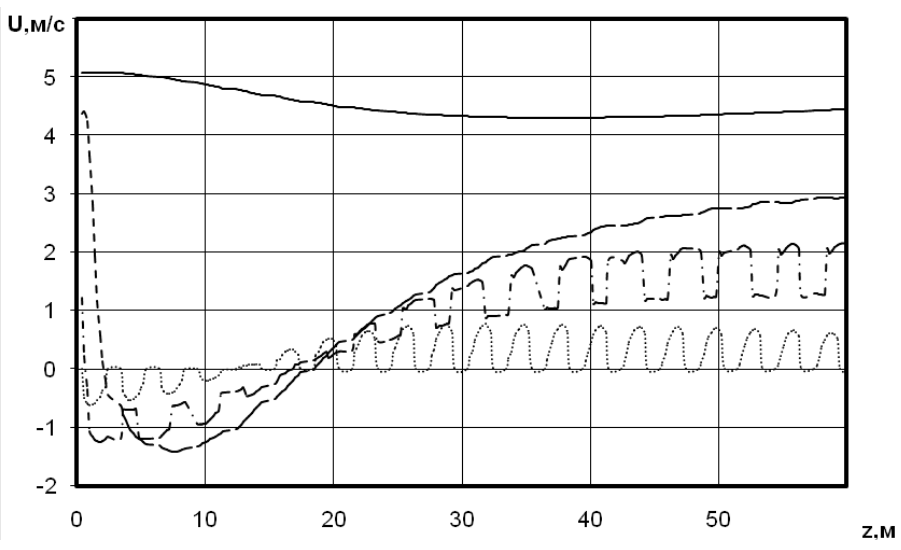

Рис. 3. Залежність середньої швидкості від координати вздовж будівлі на відстані $\cdots-0,01 \mathrm{~m} ;---0,11 ;-.-1,1 \mathrm{~m} ;--11,1 \mathrm{~m}$ від захисної конструкції будівлі в площині паралельній землі на висоті 5 м від її поверхні.

\section{ЛІТЕРАТУРА}

1. Blocken, B., Defraeye, T., Derome, D., Carmeliet, J. High-resolution CFD simulations for convective heat transfer coefficients at the facade of a low-rise building // Building and Environment. 2009. - V.44, N 12. - P. 2396-2412.

2. Marcelo G. Emmel, Marc O. Abadie, Nathan Mendes. New external convective heat transfer coefficient correlations for isolated low-rise buildings// Energy and Buildings. - 2007. - V. 39, № 3. - P. 335-342.

3. Басок Б.И., Давиденко Б.В., Новиџкая М.П., Гончарук С.М., Тыринов А.И. Теплоотдача с поверхностей ограждающих конструкций трехэтажного гражданского сооружения // Промышленная теплотехника. - 2012. - Т.34, № 2. C. 81-86.

4. Yoshihide Tominaga, Ryuichiro Yoshie, Akashi Mochida, Hiroto Kataoka, Kazuyoshi Harimoto, Tsuyoshi Nozu. Cross Comparisons of CFD Prediction for Wind Environment at Pedestrian Level around Buildings Part 2: Comparison of Results for Flow field around Building Complex in Actual Urban Area. Proceedings of The sixth asia- pacific conference of wind engineering, Seoul, Korea, September 10-12, 2005

5. Б.И. Басок, В.Г. Новиков. Численное моделирование ветровых потоков в зоне городской застройки. Відновлювальна енергетика. - 2014. № 2. - C. 46-59.

6. H. Montazeri, B. Blocken, W.D. Janssen, T. van Hooff. CFD-analysis of wind comfort on highrise building balconies: validation and application// In proceeding of: 7th International Colloquium on Bluff Body Aerodynamics and Applications (BBAA7), At Shanghai, China.

7. P.J. Richards, R.P Hoxey, B.D. Connell, D.P. Lander. Wind-tunnel modelling of the Silsoe Cube. Journal of Wind Engineering and Industrial Aerodynamics. - 2007. - V. 95. - P.- 1384-1399

8. P.J. Richards, R.P. Hoxey, L.J. Short. Wind pressures on a $6 \mathrm{~m}$ cube Journal of Wind Engineering and Industrial Aerodynamics.- 2001. - V.89. P. $1553-1564$.

9. M. Wolfshtein. The velocity and temperature distribution in one-dimensional flow with turbulence augmentation and pressure gradient, Int. J. Heat Mass Tran. - 1969. - 12 (3), - P. 301-318. 
NUMERICAL SIMULATION OF THREESTORIED BUILDINGS WITH INSET WINDOWS

\section{Novitska M.}

Institute of Engineering Thermophysics of the National Academy of Sciences of Ukraine, vul. Zhelyabova, 2a, Kyiv, 03680, Ukraine

Numerical simulation of windows inset influence on heat transfer of three-storied buildings, located in the wind flow, has been carried out. The problem based on a system of differential averaged NavierStokes equations is numerically solved. Velocity and temperature fields are obtained as a result of solving a system of differential equations. It is shown that inset impact on the aerodynamics of the flow is extends at a distance of 1 meter from the surface of building envelope. Surface heat exchange coefficient for buildings with $10 \mathrm{~cm}$ inset value for windows and plain walls has been compared. It is shown that during the numerical simulation of heat transfer and aerodynamics of buildings the existence of windows inset on the facade should be taken into account.

References 9, fig. 3.

Key words: heat transfer, aerodynamic, build, numerical simulation.

1. Blocken, B., Defraeye, T., Derome, D., Carmeliet, $J$. High-resolution CFD simulations for convective heat transfer coefficients at the facade of a low-rise building // Building and Environment. 2009. - V.44, N 12. - P. 2396-2412.

2. Marcelo G. Emmel, Marc O. Abadie, Nathan Mendes. New external convective heat transfer coefficient correlations for isolated low-rise buildings// Energy and Buildings. - 2007. - V. 39, № 3. - P. 335-342.

3. B. Basok, B.Davydenko, M. Novitska, S. Goncharuk, A. Tyrinov. Heat transfer from external surfaces of three storyed civic building. Industrial heat engineering journal - 2012. - V.34, № 2. P. 81-86. (Rus)

4. Yoshihide Tominaga, Ryuichiro Yoshie, Akashi Mochida, Hiroto Kataoka, Kazuyoshi Harimoto, Tsuyoshi Nozu. Cross Comparisons of CFD Prediction for Wind Environment at Pedestrian Level around Buildings Part 2: Comparison of Results for Flow field around Building Complex in Actual Urban Area. Proceedings of The sixth asia-pacific conference of wind engineering, Seoul, Korea, September 10-12, 2005

5. B.I.Basok, V.G.Novikov. Numerical simulation of wind flow around urban area. Vidnovluvalna energetika. - 2014. - № 2. - C. 46-59. (Rus)

6. H. Montazeri, B. Blocken, W.D. Janssen, T. van Hooff. CFD analysis of wind comfort on highrise building balconies: validation and application// In proceeding of: 7th International Colloquium on Bluff Body Aerodynamics and Applications (BBAA7), At Shanghai, China.

7. P.J. Richards, R.P Hoxey, B.D. Connell, D.P. Lander. Wind-tunnel modelling of the Silsoe Cube. Journal of Wind Engineering and Industrial Aerodynamics. - 2007. - V. 95. - P.- 1384-1399

8. P.J. Richards, R.P. Hoxey, L.J. Short. Wind pressures on a $6 \mathrm{~m}$ cube Journal of Wind Engineering and Industrial Aerodynamics.- 2001. - V.89. P. $1553-1564$.

9. M. Wolfshtein/ The velocity and temperature distribution in one-dimensional flow with turbulence augmentation and pressure gradient, Int. J. Heat Mass Tran. - 1969. - 12 (3), - P. 301-318.

Получено 08.04.2015 Received 08.04.2015 